\title{
Power Flow Controller for Meshed Systems with a Fractionally Rated BTB Converter
}

\author{
Rajendra P. Kandula Amrit Iyer Rohit Moghe Jorge E. Hernandez Deepak Divan \\ School of Electrical and Computer Engineering \\ Georgia Institute of Technology \\ Atlanta, GA, 30332 \\ krprasad@gatech.edu
}

\begin{abstract}
The increasing load demand, increasing level of penetration of renewable energy and limited transmission infrastructure investments have significantly increased the need for a smart dynamically controllable grid. Existing solutions based on FACTS devices, are complex and expensive to implement at transmission level or even subtransmission level voltages. This paper proposes a novel power flow controller for dynamic control of active/reactive power in a meshed network. The proposed controller is realized by augmenting a transformer with a fractionally rated bi-directional Back to Back (BTB) converter. The main advantages of the proposed converter are the fractional converter rating, reliability and scalability.
\end{abstract}

\section{INTRODUCTION}

The increasing load demand, increasing level of penetration of renewable energy and limited transmission infrastructure investments have significantly increased the need for a smart dynamically controllable grid. Traditionally, power flow control has been achieved by generator control, shunt VAR compensation and LTC tap settings. However, the range of control achieved is not very significant and the dynamic response is very slow. Over the last two decades, a number of Flexible AC transmission systems (FACTS) devices, have been proposed for dynamic power flow control. The Unified power flow controller (UPFC) [1] and Back to Back (BTB) HVDC link [2], two common examples, consist of two bidirectional voltage source converters with a common DC link and provide a wide control range $(+/-1$ p.u.) for both active and reactive power. However, for a 1 p.u. control range the converter has to be rated for at least 2 p.u. (two converters of 1 p.u. each). Building such high power controllers for transmission or sub-transmission systems is extremely complex and expensive. The size and complexity may affect reliability. Static Synchronous series converter (SSSC) is another common method for power flow control [3]. Though it is fractionally rated, it needs an external power source for independent control of active and reactive power. The decreased reliability, high complexity and large investments involved with implementation of FACTs devices have prevented them from large scale adoption.

A new approach for dynamic power flow control based on a fractionally rated direct AC-AC converter has also been proposed in literature. The Controllable Network Transformer (CNT) consists of a load tap changing transformer augmented by a direct AC-AC converter to provide vernier control of both voltage magnitude and phase angle [4]. The AC/AC converter is fractionally rated making it cost effective and it does not have any dc capacitors. But scaling of direct $\mathrm{AC} / \mathrm{AC}$ converters, ensuring dynamic voltage sharing, and reliable operation under complex fault modes, is yet to be proved in practice.

This paper proposes a novel power flow controller that takes the best of the above two different approaches. The proposed controller is realized by augmenting a transformer with a fractionally rated bi-directional BTB converter. The converter achieves fractional rating because of the fractional voltage, giving it a unique advantage when scaling up to transmission level voltages. A fail normal switch connected across the converter bypasses the controller in case of a contingency. The small DC capacitor avoids commutation issues associated with direct $\mathrm{AC} / \mathrm{AC}$ converter based CNT. Features like the fractional converter rating, high reliability and scalability makes this controller a viable option for dynamic power flow control in a meshed grid.

\section{CONVERTER TOPOLOGY}

The proposed controller is realized by augmenting a transformer with a fractionally rated BTB converter. Single phase implementation of the proposed converter is shown in Figure 1. The converter is connected across the taps $(+n,-n)$ of an auto transformer. The converter consists of a transformer side converter (TSC) and a line side converter (LSC) connected through a common capacitor link. A fail normal switch, realized by two antiparallel thyristors, is connected across the converter. For retrofit applications an existing Load tap changing (LTC) transformer can be used instead of an autotransformer. 


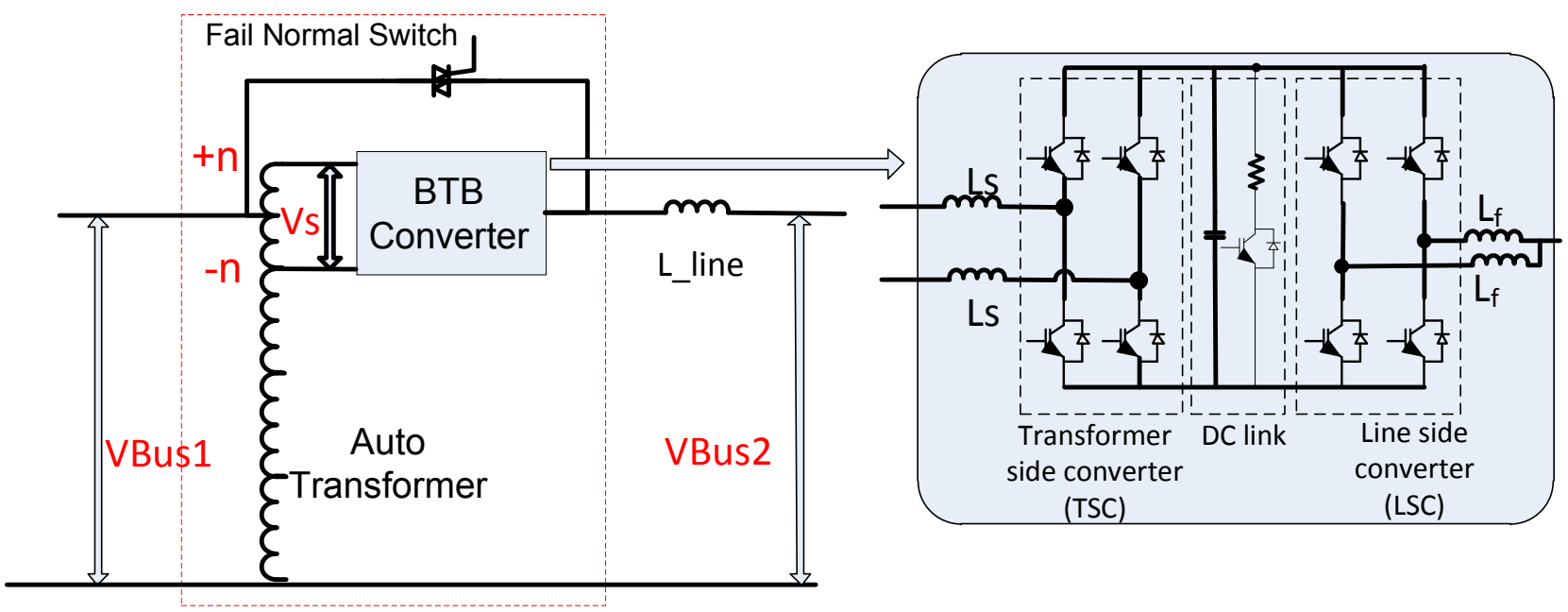

Power Flow Controller

Figure 1: Power flow controller with a fractionally rated BTB converter

The main advantages of the proposed converter are the fractional converter rating, high reliability and scalability. The converter rating is only a fraction of the total controlled power rating as the switches have to handle only a fraction of the transformer rated voltage. Since the converter achieves fractional rating because of the fractional voltage and not the current, such a configuration gives it a unique advantage when scaling up to transmission level voltages. At very high voltages $(>139 \mathrm{kV})$, where series operation of IGBTs cannot be avoided even with fractional rating, the converter can be easily scaled by implementing multi-level topologies, which is a mature technology $[4,5]$. The 3-level single phase implementation of the proposed controller is shown in Figure 2. Finally, in case of a converter failure or line side fault, the fail-normal switch bypasses the controller and in case of a LTC based solution, retains the passive transformer functionality. This avoids single-point failures, and increases system reliability.

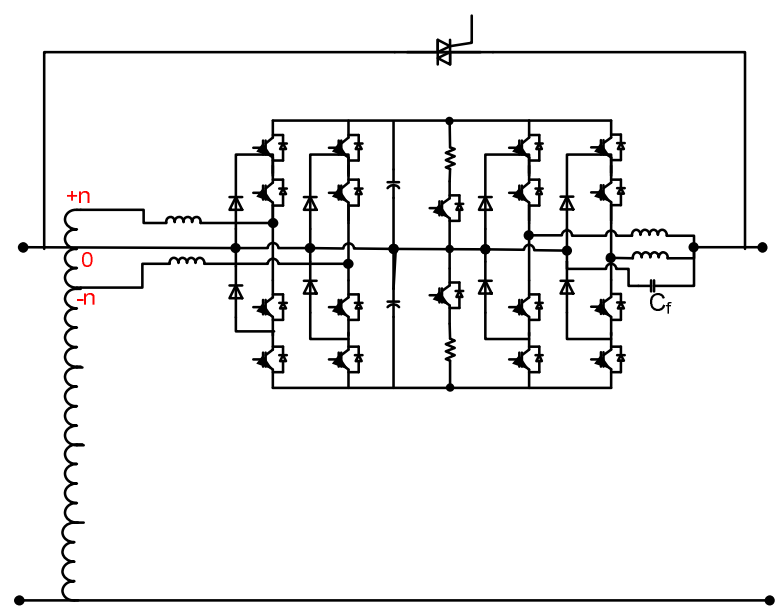

Figure 2: 3-level implementation

\section{PRINCIPLE OF POWER FLOW AND CONTROL RANGE OF OPERATION}

Principle: Dynamic power flow control, both active and reactive, is achieved by actively controlling the phase and magnitude of the transformer voltage. As shown in Figure 3 , the controller synthesizes converter input voltage $\left(V_{s}\right)$ to generate a voltage $\left(V_{c o n v}\right)$ that can be of different magnitude and phase compared to $V s$. As a result, the phase and magnitude of the output voltage $\left(V_{\text {out }}\right)$, resultant of Bus 1 voltage $\left(V_{l}\right)$ and $V_{\text {conv }}$, can be controlled to achieve both active and reactive power control.

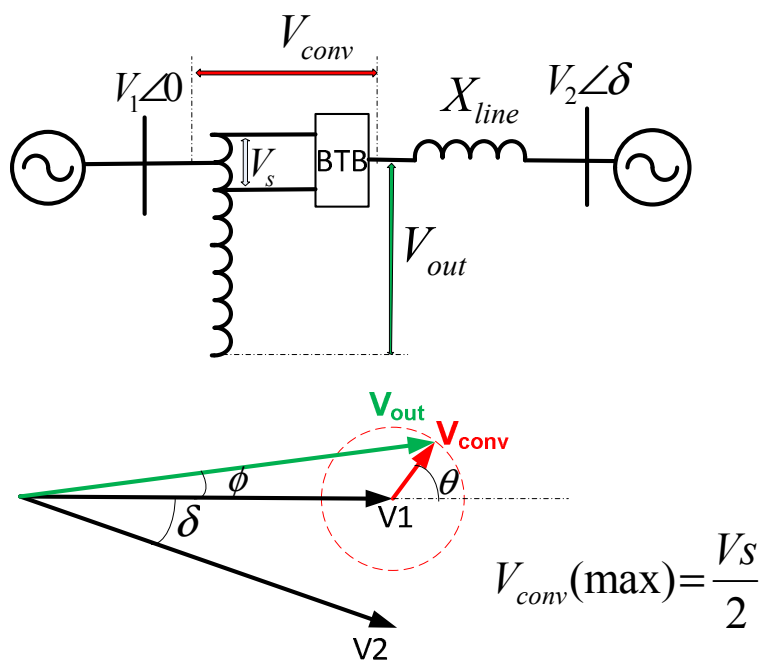

Figure 3: Principle of operation

Range: The series voltage that the controller can generate is a function of input voltage $V_{s}$, which in turn depends on the transformer taps across which the 
converter is connected. As shown in Figure 3, the voltage range is a disc with radius of $\mathrm{V}_{\mathrm{s}} / 2$.

The power flow control range of the controller is a function of input voltage $V_{s}$, line impedance $\left(\mathrm{X}_{\text {line }}\right)$ and phase difference $(\delta)$ between the two buses. The active power $(P)$ and sending end reactive power $\left(Q_{l}\right)$ and receiving end reactive power flow $\left(Q_{2}\right)$ equations with the proposed converter are given below.

$$
\begin{gathered}
P=\frac{V_{\text {out }} * V_{2}}{X_{\text {line }}} * \sin (\delta+\emptyset) \\
Q_{1}=\frac{V_{\text {out }}}{X_{\text {line }}}\left(V_{\text {out }}-V_{2} * \cos (\delta+\emptyset)\right) \\
Q_{2}=\frac{V_{2}}{X_{\text {line }}}\left(V_{2}-V_{\text {out }} * \cos (\delta+\emptyset)\right)
\end{gathered}
$$

where $V_{\text {out }}=\sqrt{V_{1}^{2}+V_{\text {conv }}^{2}} \emptyset=\tan ^{-1} \frac{V_{\text {conv }} \sin \theta}{V_{1}+V_{\text {conv }} \cos \theta}$

For a $138 \mathrm{kV}$ system, with the system parameters given in Table 1, the power flow control range is shown in Figure 4 for different operating conditions. The controller does provide a maximum of +/- 38 MVA control capability for all operating conditions though the controller tends to lose range of independent control of active power and sending end reactive power as $\delta$ increases. The impact of $\delta$ on independent control of receiving end reactive power is negligible. Though the controller provides a control range of 38MVA, the converter itself is rated only $6.8 \mathrm{MVA} / 8 \mathrm{kV}$ for $\delta=$ $2 \mathrm{deg}$ and $18 \mathrm{MVA} / 8 \mathrm{kV}$ for $\delta=10 \mathrm{deg}$ respectively. But at $\delta=20 \mathrm{deg}$, the converter is rated for 31 MVA. As the $\delta$ increases, the converter reduces its controllability $\mathrm{v} / \mathrm{s}$ fractional rating advantage but most of the short to medium lines have $\delta<5 \mathrm{deg}$ where the proposed controller is more applicable.

Table 1: $138 \mathrm{kV}$ test system Parameters

\begin{tabular}{ll}
\hline Parameter & Value \\
Voltage & $138 \mathrm{kV} \mathrm{L-L}, 80 \mathrm{kV} \mathrm{L-G}$ \\
Line & $30 \mathrm{miles}, 0.168+\mathrm{j} 0.79 \mathrm{ohms} / \mathrm{mile}$ \\
Taps (n) & $+/-5 \%$ \\
\hline
\end{tabular}

Shunt VAR capability: The proposed controller also has limited shunt VAR capability. The shunt VAR range is the same as the converter rating. Since the converter is fractionally rated the shunt VAR capability is also limited. The range is given by the following equation.

$$
Q_{s h}=2 n * \sqrt{3} * V_{B u s} * I_{\text {conv_rating }}
$$

where $V_{B u s}$ is the L-L voltage, $n$ is the transformer tap ratio and $I_{\text {conv_rating }}$ is the current rating of the converter. The methodology for series VA and shunt VAR control is explained in the next section.
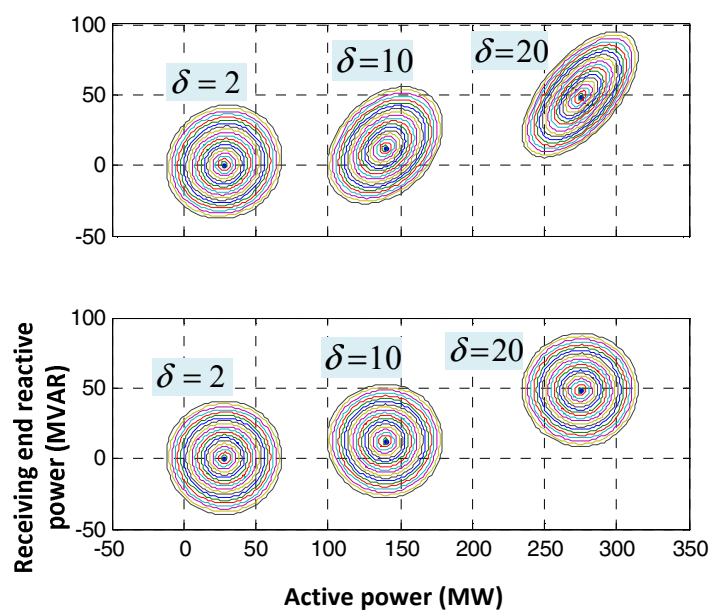

Figure 4: Range of power flow control

\section{CONVERTER CONTROL}

The power flow in the proposed converter, because of the way it is implemented, is different from standard BTB operation. It has two components - common mode and differential mode as shown in Figure 5. The common mode power (blue) is unique to the proposed system and is controlled by the LSC to generate requisite power flow in the line. LSC can generate either $\left(V_{s}+V_{d c}\right) / 2$ or $\left(V_{s}-V_{d c}\right) / 2$ depending on the LSC switch position. Any voltage waveform that remains within the envelope of $\left(V_{s}+V_{d c}\right) / 2$ and $\left(V_{s}-V_{d c}\right) / 2$ can be synthesized by switching between the two extremes to generate $V_{\text {comm }}$. This implies that the maximum fundamental voltage that can be generated by the converter w.r.to the center tap has a peak of $V_{d c} / 2$. Typically, $V_{d c}$ is controlled to be peak of $V_{s}$, hence, as shown in Figure 3, the converter has a circular voltage range with a maximum value of $V_{s} / 2$. $V_{\text {comm }}$ is controlled to regulate the common mode current $I_{\text {comm }}$ which is same as the line current.

The differential power component (green) shuffles energy between the transformer and the dc bus through the TSC. As in a typical BTB converter, active component of $I_{\text {diff }}$ is controlled to regulate the mean DC capacitor voltage and reactive component is controlled to regulate the shunt VAR.

The converter control scheme, shown in, consists of common mode control and differential mode control blocks. For desired active power and series VAR, the master control sets the current references for common mode control. The control is achieved in d-q synchronous reference frame. The desired line currents $I_{c o m m}^{r e f}$ are then compared with the actual current $I_{\text {comm }}$ and the error is propagated through the PI controller, which in turn generates converter output voltage reference $V_{\text {comm }}^{\text {ref }}$. The reference voltage is then compared with carrier wave to generate switching pulses for the LSC. 


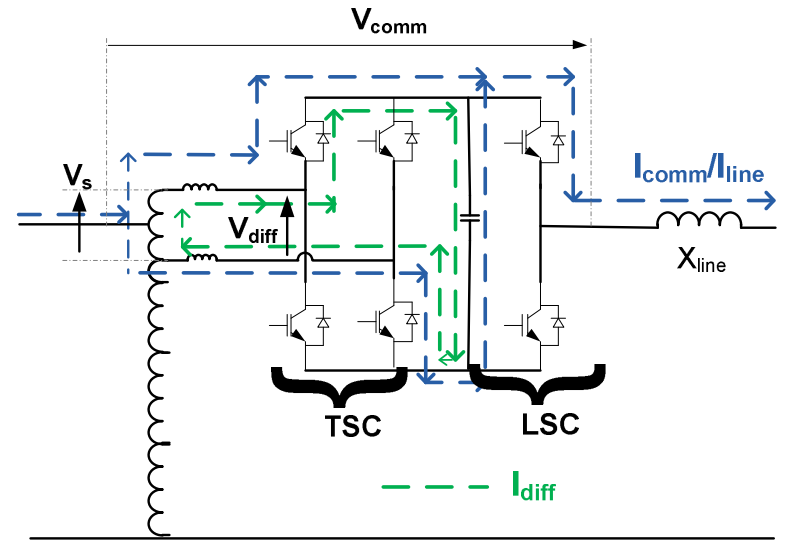

Figure 5: Common and differential mode currents

The objective of the differential mode control is to maintain the average dc link voltage $V_{d c, 0}$ at a desired value and also control the shunt VAR. The average value of the dc link voltage is extracted with a low pass filter and then compared with the reference value. The voltage error is fed to PI regulator which in turn generates TSC reference current $I_{\text {diff,d }}^{r e f}$. The master control generates the reference for the reactive component of the differential current $I_{d i f f, q}^{r e f}$ as per the shunt VAR requirements. As in common mode control, the differential currents are regulated by generating appropriate switching pulses for the TSC.

\section{SIMULATION RESULTS}

A 2-bus $138 \mathrm{kV}$ system similar to the one in Figure 3 and described in Table 1, is simulated to demonstrate the functionality of the proposed power flow controller. The converter parameters are given in Table 2. The control parameters are designed using standard bode plot techniques and are given in Table 3.

At $\delta=2 \mathrm{deg}$, the power flow in the line without the controller is $28 \mathrm{MW}$. As shown in Figure 7, the controller can vary power flow from $66 \mathrm{MW}$ to $-10 \mathrm{MW}$, thereby, providing a control range of $38 \mathrm{MW}$. The reactive power is held constant while the active power is varied demonstrating independent control. Similarly, the reactive power control is also shown.

The converter input voltage $V_{s}$, line current and converter voltage $V_{\text {conv }}$ at maximum active power range are shown in Figure 8. The maximum $V_{\text {conv }}$ that the converter can generate is half of $V_{s}$. The differential current being controlled to regulate the dc bus voltage is shown in Figure 9. A controllability range of $+/-38$ MW/MVAR is achieved with a converter rating of $10 \%$ of the power being controlled. Since it is connected between $+/-5 \%$ taps, the converter has to handle peak voltage of $12 \mathrm{kV}\left(V_{s}\right)$ only. The same implementation with standard BTB converters would need either switches that can handle peak voltages of $200 \mathrm{kV}$ or low frequency step down transformers increasing the cost of implementation. The advantage of the proposed controller in terms of lower cost and reduced complexity in implementation is demonstrated.

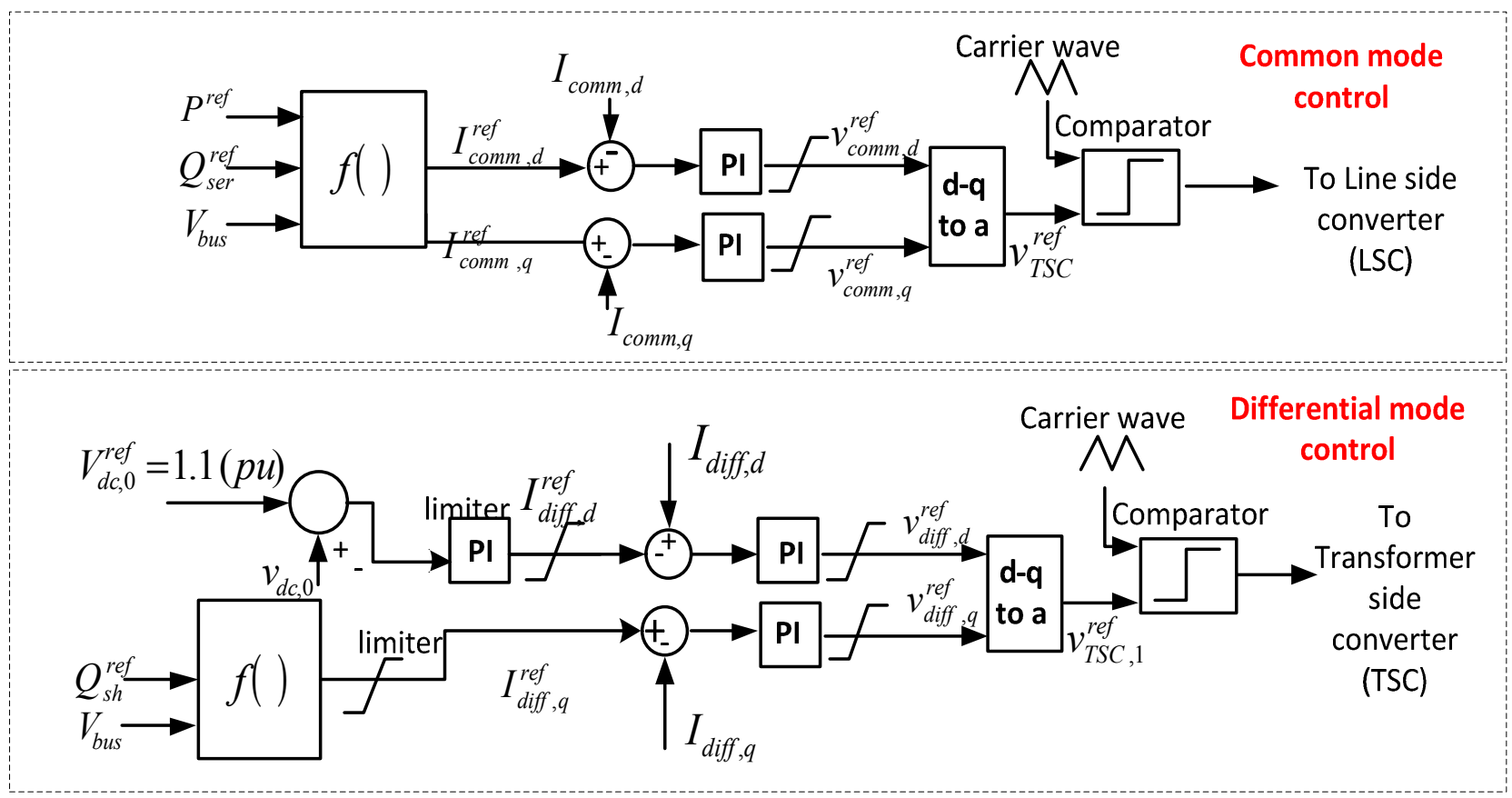

Figure 6: Control scheme 
Table 2: Converter parameters

\begin{tabular}{ll}
\hline Parameter & Value \\
\hline Vs & $8.0 \mathrm{kV}$ \\
Vdc & $12.5 \mathrm{kV}$ \\
Cdc & $1 \mathrm{mF}$ \\
Ldiff & $4 \mathrm{mH}$ \\
Lf & $1 \mathrm{mH}$ \\
Cf & $50 \mathrm{microF}$ \\
$\boldsymbol{\delta}$ & $2 \mathrm{deg}$ \\
\hline
\end{tabular}

Table 3: Converter control parameters

\begin{tabular}{lc}
\hline Parameter & Value \\
\hline & Differential mode \\
Vdc (base) & $12.5 \mathrm{kV}$ \\
Idiff (base) & $500 \mathrm{~A}$ \\
Kp,ki (voltage loop) & 4,10 respectively \\
Kp,ki (current loop) & $0.05,0.5$ respectively \\
& Common mode \\
Vconv (base) & $4 \mathrm{kV}$ \\
Iline (base) & $800 \mathrm{~A}$ \\
$\mathrm{Kp}, \mathrm{ki}$ & $0.1,0.5$ respectively \\
\hline
\end{tabular}
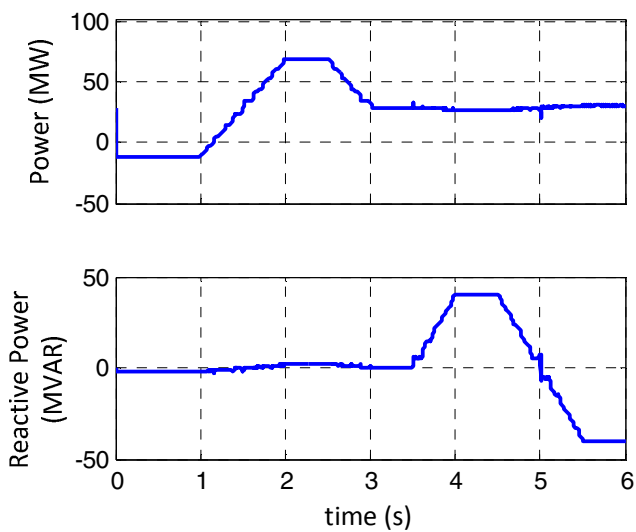

Figure 7: Dynamic active and reactive power control
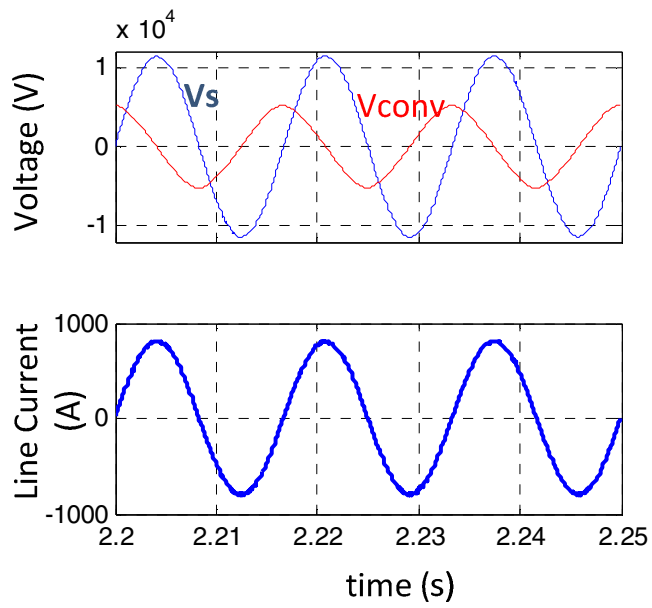

Figure 8: Converter input voltage, output voltage and line current

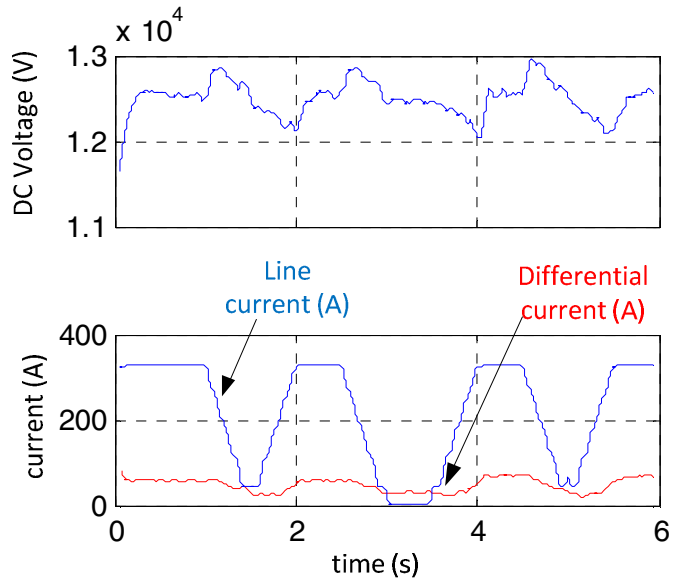

Figure 9: DC bus voltage, line current (rms) and differential current (rms)

\section{SMALL SIGNAL AND FREQUENCY DOMAIN MODELS}

Simplified models of the converter are necessary for system studies. The small signal model and steady state model for the proposed converter are derived using similar basic principles used in UPFC model derivation [6].

Small signal model: The small signal model is obtained by averaging the switching frequency dynamics. It can be represented by a series and a shunt controlled voltage source as shown in Figure 10. The equations governing the controlled voltage sources are given by eq.(5) -eq.(7.

$$
\mathrm{v}_{\mathrm{comm}}=\mathrm{mi}_{\mathrm{comm}} * \sin \left(\omega \mathrm{t}+\phi_{\mathrm{comm}}\right) * \frac{\mathrm{v}_{\mathrm{dc}}}{2}
$$

$$
\mathrm{v}_{\text {diff }}=\mathrm{mi}_{\text {diff }} * \sin \left(\omega t+\phi_{\text {diff }}\right) * \mathrm{v}_{\mathrm{dc}}
$$

where $m i_{\text {comm }}$ is the modulation index of the LSC and $m i_{\text {diff }}$ is the modulation index of the TSC.

The capacitor dynamics are retained by the flowing equation.

$$
\begin{gathered}
\mathrm{C}_{\mathrm{dc}} * \frac{\mathrm{d}\left(\mathrm{v}_{\mathrm{dc}}\right)}{\mathrm{dt}}=\frac{P_{d c_{-} d i f f}-P_{d c_{-} \text {comm }}}{v_{d c}} \\
\text { where } \quad \mathrm{P}_{\mathrm{dc} \_ \text {comm }}=\int \mathrm{v}_{\text {comm }} * \frac{\mathrm{i}_{\text {line }}}{2} \text { and } \\
\mathrm{P}_{\mathrm{dc} \_ \text {diff }}=\int \mathrm{v}_{\text {diff }} * \mathrm{i}_{\text {diff }}
\end{gathered}
$$


The small signal model is compared against the time domain model in Figure 11. As seen in the figure, the line current from the small signal model is same as the time domain model except for the switching frequency ripple. Similarly in Figure 12, the dc bus voltage from the small signal model matches the time domain model except for the second harmonic ripple.

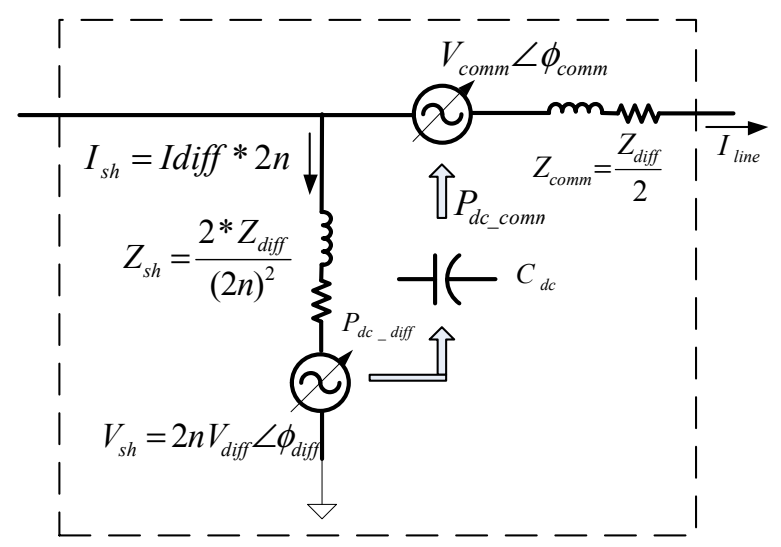

Figure 10: Small signal model

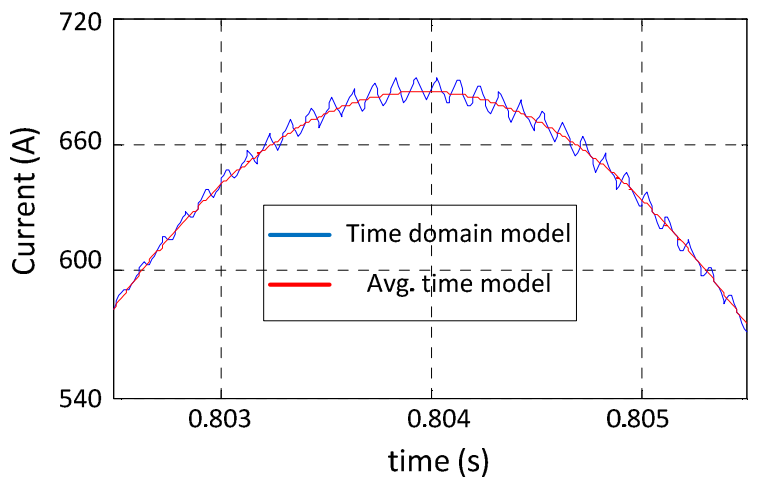

Figure 11: Line current: Time domain and small signal model

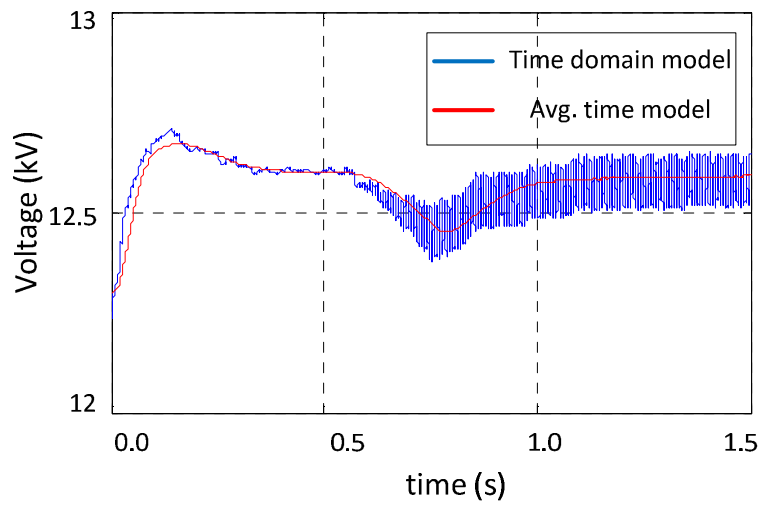

Figure 12: Vdc: Time domain and small signal model
Frequency domain model: In the frequency domain model, the controller is modeled as a P-Q injection model at either buses of the line as shown in Figure 13. In this model, the capacitor dynamics are also ignored. The $\mathrm{P}$ and $\mathrm{Q}$ equations of the model are given by eq.(8-(10.

where

$$
\begin{gathered}
P_{\text {ser }}=\frac{V_{\text {out }} * V_{2}}{X_{\text {line }}} * \sin \left(\delta+\emptyset_{\text {comm }}\right) \\
Q_{1}=Q_{1, \text { ser }}+Q_{1, \text { sh }}
\end{gathered}
$$

$$
\begin{aligned}
& Q_{1, \text { ser }}=\frac{V_{1, \text { eff }}}{X_{\text {line }}}\left(V_{1, \text { eff }}-V_{2} \cos \left(\delta+\emptyset_{\text {comm }}\right)\right) \\
& \begin{array}{c}
Q_{1, \text { sh }}=\frac{2 n V_{1}}{2 X_{\text {diff }}}\left(2 n V_{1}-V_{\text {diff }} \cos (\delta\right. \\
\left.\left.+\emptyset_{\text {diff }}\right)\right)
\end{array} \\
& Q_{2, \text { ser }}=\frac{V_{2}}{X_{\text {line }}}\left(V_{2}-V_{\text {out }} * \cos (\delta+\emptyset)\right) \\
& \text { where } V_{\text {out }}=\sqrt{\left(V_{1}^{2}+V_{\text {conv }}^{2}\right)}, \\
& \varnothing=\tan ^{-1}\left(\frac{V_{\text {conv }} * \sin \theta}{V_{1}+V_{\text {conv }} * \cos \theta}\right) \text { and } n \text { is the tap ratio. }
\end{aligned}
$$

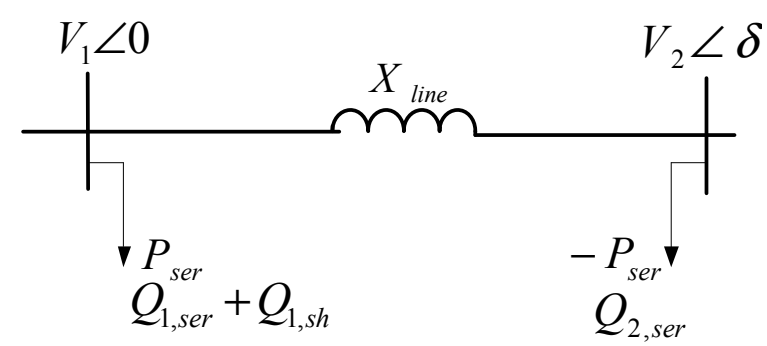

Figure 13: Frequency domain model

\section{50 kVA EXPERIMENTAL SETUP}

To demonstrate the functionality of the proposed power flow controller, a $50 \mathrm{KVA}$ setup is built in the laboratory. The two bus system is achieved by the schematic shown in Figure 14.

. It consists of a single phase $240 \mathrm{~V}$ source, two sets of $240 \mathrm{~V} / 1320 \mathrm{~V}$ transformers with $+/-120 \mathrm{~V}$ taps representative of the two buses in Figure 3. The BTB converter is connected to one of the transformer sets between $+/-120 \mathrm{~V}$ taps. The BTB converter itself is built with 3- The test setup is pictured in Figure 14(b). 3-level IGBT poles using 1700V 200A Dynex IGBTs are built. The freewheeling diodes used are $1700 \mathrm{~V}$ Semikron devices. The dc capacitor used is 730 microF, line inductance is $2 \mathrm{mH}$ and the transformer side inductors are $300 \mu \mathrm{H}$ each. 


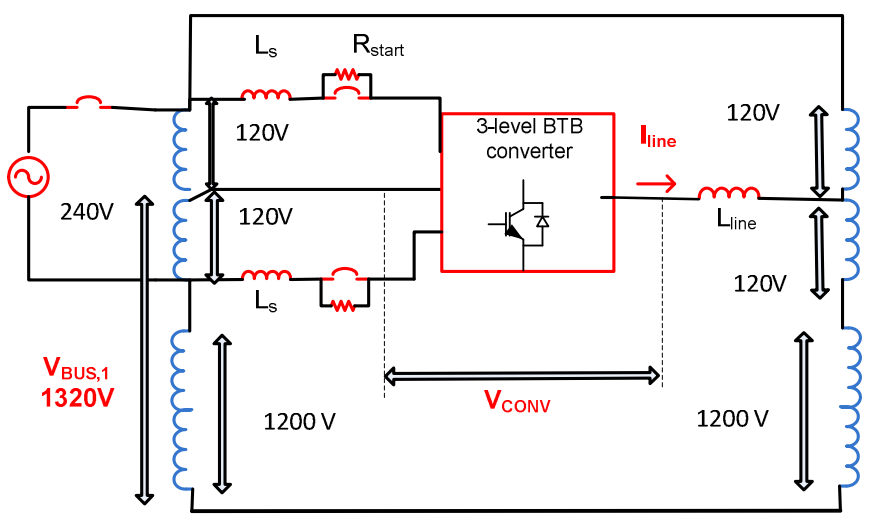

(a)

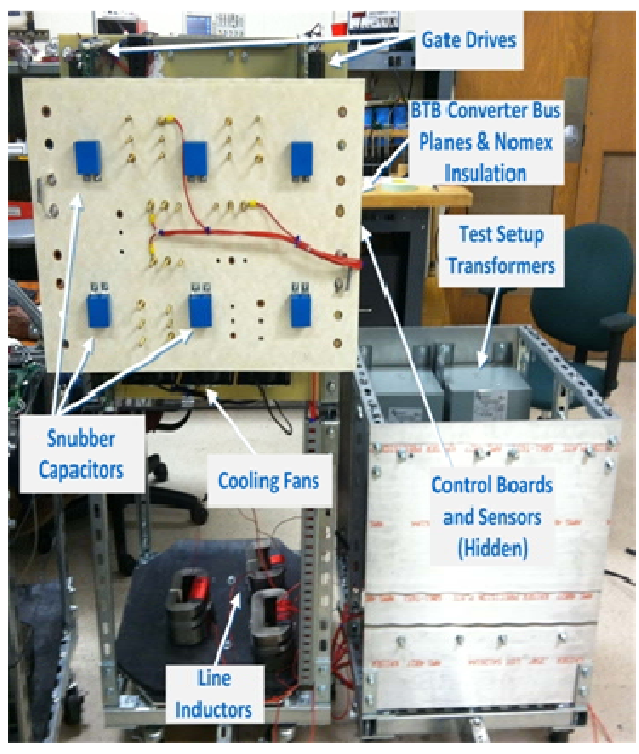

(b)

Figure 14: (a) Schematic of $50 \mathrm{kVA}$ 2-bus test system (b) 50 KVA lab setup

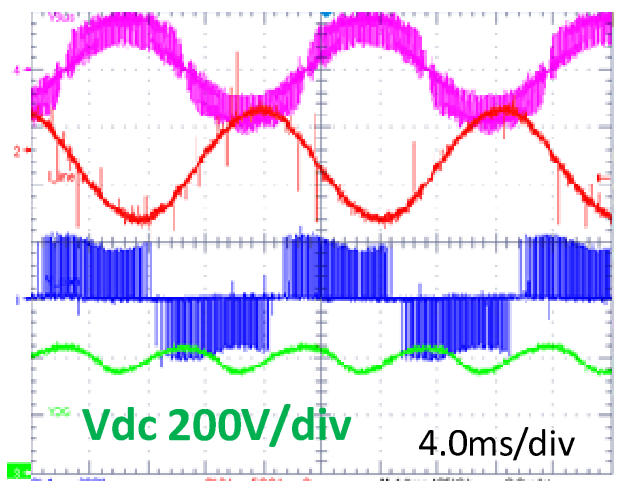

(a)

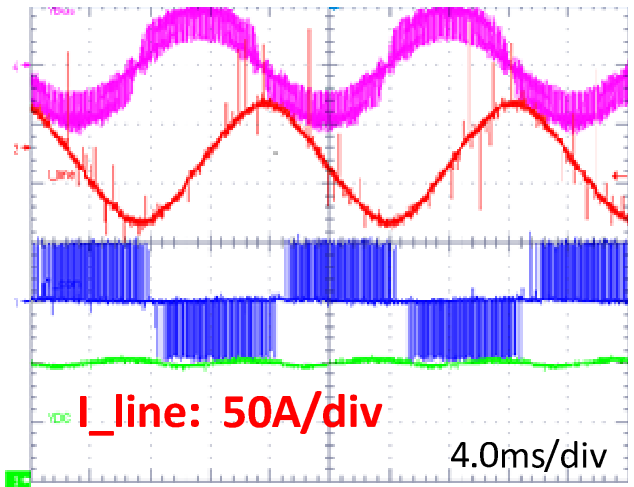

(c)

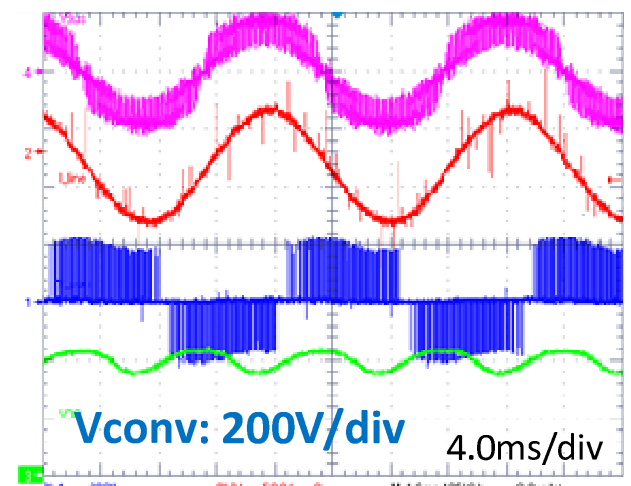

(b)

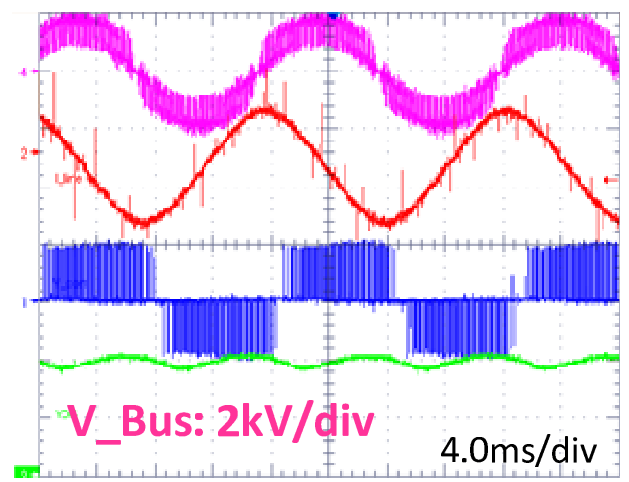

(d)

Figure 15: Experiment results (a) Positive power (b) Negative power (c) Lagging VAR (d) Leading VAR 
Without the converter, the bus on either end has the same voltage magnitude and phase and hence there is no power transfer across the line. With the proposed converter the effective voltage of Bus 1 is controlled to be different from Bus 2, in magnitude or phase or both, to induce power transfer across the line. The four quadrant control results at $50 \mathrm{kVA}$ are shown in Figure 15. The converter voltage ( $V$ conv), the voltage impressed by the TSC on the line inductor, induce a $35 \mathrm{~A}$ line current (I_line) at a bus voltage of $1320 \mathrm{~V}$. The TSC is controlling the DC capacitor voltage at $120 \%$ of the peak of Vs. As shown in Figure 16 \& Figure 17, the active power is ramped from 0 to $46 \mathrm{~kW}$ and then to -46 $\mathrm{kW}$ to demonstrate independent and dynamic controllability of active power. While $46 \mathrm{kVA}$ is being controlled, the converter rating is only $10 \mathrm{kVA}$. The advantage of the proposed controller in terms of lower cost and reduced complexity in implementation is experimentally demonstrated.

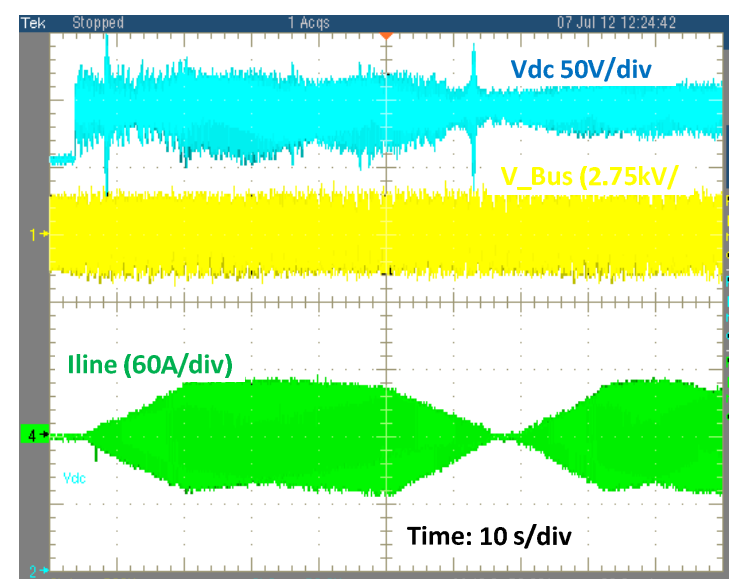

Figure 16: Dynamic control: Vdc, Vs and Iline

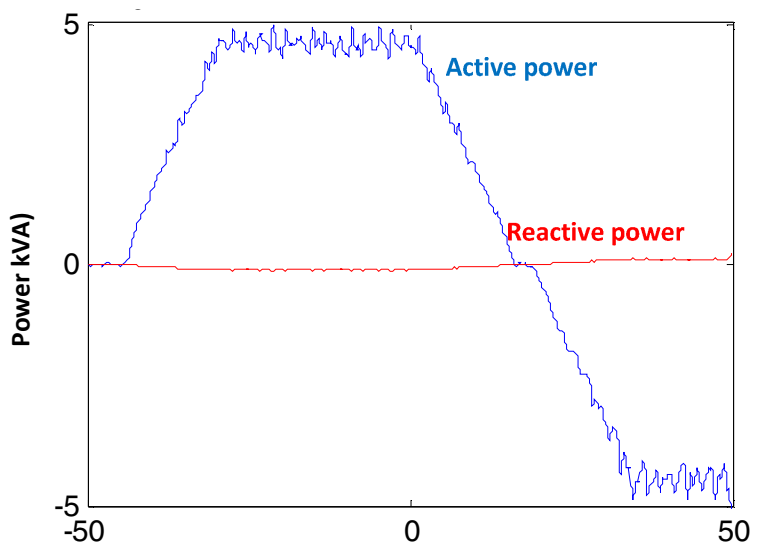

Figure 17: Dynamic control: Active and reactive power

\section{CONCLUSION}

This paper presents a novel power flow controller for dynamic control of active/reactive power in a meshed network. The controller structure, principle of operation and control range are presented. The power flow control ability is demonstrated through simulation results. A $50 \mathrm{kVA}$ lab prototype is built and results at $50 \mathrm{~kW}$ demonstrate the functionality and the advantages of the proposed controller. The fractional rating of the converter obtained though fractional voltage rating gives the proposed converter a unique advantage in scaling for transmission level voltages, thereby, providing a simplified cost effective method for power flow control.

\section{ACKNOWLEDGEMENT}

The authors acknowledge James Steinberg in his help with building the test fixtures.

\section{REFERENCES}

[1] L. Gyugyi, "Unified power-flow control concept for flexible AC transmission systems," Generation, Transmission and Distribution, IEE Proceedings C, vol. 139, pp. 323-331, 1992.

[2] B. Bagen, D. Jacobson, G. Lane, and H. M. Turanli, "Evaluation of the Performance of Back-to-Back HVDC Converter and Variable Frequency Transformer for Power Flow Control in a Weak Interconnection," in Power Engineering Society General Meeting, 2007. IEEE, 2007, pp. 1-6.

[3] L. Gyugyi, C. D. Schauder, and K. K. Sen, "Static synchronous series compensator: a solid-state approach to the series compensation of transmission lines," Power Delivery, IEEE Transactions on, vol. 12, pp. 406-417, 1997.

[4] T. Larsson, A. Petersson, A. Edris, D. Kidd, and F. Aboytes, "Eagle Pass back-to-back tie: a dual purpose application of voltage source converter technology," in Power Engineering Society Summer Meeting, 2001. IEEE, 2001, pp. 1686-1691 vol.3.

[5] B. Abrahamsson, "Estlink HVDC Light in 19 months," in IET Power Convention, 2007, 2007, pp. 1-34.

[6] A. Nabavi-Niaki and M. R. Iravani, "Steady-state and dynamic models of unified power flow controller (UPFC) for power system studies," Power Systems, IEEE Transactions on, vol. 11, pp. 1937-1943, 1996. 